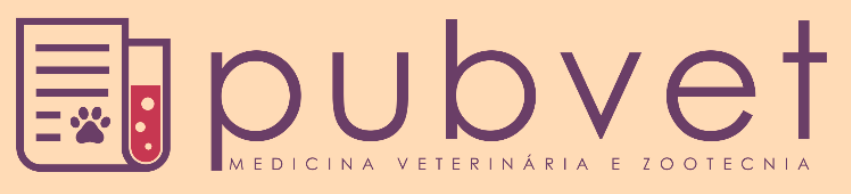

https://doi.org/10.31533/pubvet.v15n09a911.1-7

\title{
Conhecimento dos consumidores sobre a atuação do médico veterinário na cadeia produtiva do leite
}

\author{
Ester Sílvia Borges de Morais ${ }^{1^{*} \bullet}$, Isadora Virissimo Adorno ${ }^{1 \bullet}$, Karla Vitória Alves Sampaio ${ }^{1} \bullet$, \\ Osvaldo José da Silveira Neto ${ }^{2}{ }^{\circ}$
}

${ }^{1}$ Discentes da Pontifícia Universidade Católica de Goiás, Escola de Ciências Agrárias, Goiânia, Goiás, Brasil.

${ }^{2}$ Professor Orientador da Pontifícia Universidade Católica de Goiás, Escola de Ciências Agrárias, Goiânia, Goiás, Brasil

*Autor para correspondência, estersbm@gmail.com

Resumo. Este trabalho teve como objetivo analisar o conhecimento dos residentes dos municípios de Aparecida de Goiânia e Goiânia, Goiás, acerca da atuação do Médico Veterinário na cadeia produtiva do leite. Além disso foi questionado quais os cuidados realizados pelos consumidores antes de adquirir e ingerir o leite, como também conhecimento sobre transmissão de doenças via ingestão de leite. Durante o mês de maio e julho/2020 foi disponibilizado um questionário via plataforma Google Forms, contendo 14 questões as quais abordavam o tema. No total 230 pessoas responderam o formulário. Dentro dos resultados obtidos, observou-se que cerca de $83,9 \%$ consomem o produto leite UHT (Ultra High Temperature) e 16,1\% adquirem ele cru, sendo que desses 2,5\% não realizam o processo de fervura antes de consumir. Apesar de $92,2 \%$ dos questionados terem o hábito de consumir o leite (UHT, Cru) mais de uma vez semanalmente, apenas $60,4 \%$ afirmam ter conhecimento de transmissão de doenças. Além disso, os dados apontaram que dos 230 entrevistados 69 (30\%) não tem conhecimento da transmissão de doenças via ingestão de leite e nem da procedência do produto. Ao questionar a atuação do Médico Veterinário, 70,9\% acreditam que este profissional atua em todas as áreas disponibilizadas nas opções, sendo elas: nutrição animal, inspeção de laticínios, inspeção da ordenha, qualidade do leite e apenas $0,9 \%$ da população total entrevistada, afirmaram que o Médico Veterinário não atua em nenhuma área que foi citada. Deste modo, conclui que a maior parte dos entrevistados possui conhecimento sobre o leite ser um possível veículo de transmissão de doenças, porém uma parcela significativa não. Percebeu que há uma falta de conhecimento da população sobre a procedência do produto que consome. Com os dados finais da pesquisa conclui-se que uma elevada porcentagem dos entrevistados que residem nos municípios de Goiânia e Aparecida de Goiânia conhece a atuação do Médico Veterinário na cadeia de produção leiteira, sendo um importante profissional na garantia da Saúde Pública.

Palavras-chave: alimento, consumidores, saúde pública

\section{Consumers' knowledge of the veterinary doctor's role in the milk production chain}

Abstract. This study aimed to analyze the knowledge of residents of the cities of Aparecida de Goiânia and Goiânia, Goiás, about the role of the Veterinary Doctor in the milk production chain and, beyond that, it was questioned what care consumers take before purchasing and ingesting milk, also their knowledge about disease transmission by milk intake. During the month from May to July, 2020, a questionnaire was provided on Google Forms platform, containing 14 questions which addressed the topic. In total 230 people answered the form. Within the results obtained, it was observed that around $83.9 \%$ 
consume the product UHT milk (Ultra High Temperature) and $16.1 \%$ acquires it raw, of which $2.5 \%$ do not undergo the boiling process before consuming. In spite of $92.2 \%$ of respondents have the habit of consuming milk (UHT, raw) more than once a week, only $60.4 \%$ reported having knowledge of disease transmission. In addition, the data pointed out that of the 230 respondents $69(30 \%)$ are unaware of the transmission of diseases by milk ingestion or the origin of the product. When questioned about the role of the Veterinary Doctor, $70.9 \%$ believe that this professional works in all areas available in the options, being them: animal nutrition, dairy inspection, milking inspection, milk quality and only $0.9 \%$ of the population total interviewed, stated that the Veterinary Doctor does not act in any area that was mentioned. Therefore, it concludes that most of the interviewees has knowledge about milk being a possible vehicle for the transmission of diseases, but a significant portion does not. It was noticed that there is a lack of knowledge among the population about the origin of the product they consume. With the final data of the research it is concluded that a high percentage of the interviewees who live in the cities of Goiânia and Aparecida de Goiânia knows the role of the Veterinary Doctor in the dairy production chain, being an important professional in guaranteeing Public Health.

Keywords: Food, consumers, public health

\section{Introdução}

O leite é essencial para dieta de indivíduos de todas as faixas etárias e classes sociais, por ser um dos alimentos mais completos, devido em sua composição possuírem vitaminas, lipídios, proteínas e sais minerais (Silva \& Coelho, 2019). Segundo Lima et al. (2016) o leite deve apresentar algumas características como alto valor nutritivo, sabor agradável, ausência de agentes patogênicos e contaminantes, baixa carga microbiana e reduzida contagem de células somáticas para ser considerado um produto de boa qualidade (De Vries et al., 2011). Dentre os fatores que afetam a qualidade estão higiene da produção e pessoal, sanidade do ambiente, armazenamento, embalagem, transporte, temperatura (Bodenmüller Filho et al., 2010). Caso não atendidas as regras rígidas de produção, pode propiciar a propagação de patógenos no leite, pois a contaminação microbiológica é provinda das condições insatisfatórias de higiene das fases de produção.

Conforme a Organização Mundial da Saúde (OMS) são transmitidas doenças bacterianas e doenças viróticas, sendo que as principais são brucelose, listeriose, salmonelose, intoxicações alimentares. Sendo recomendado que os indivíduos não consumam leite e derivados crus, pois podem ser um meio de contaminação, devido à falta de fiscalização e inspeção sanitária tornando-o impróprio para consumo e podendo fator de risco para saúde humana (Matsubara et al., 2011; Ribeiro Júnior et al., 2020).

De acordo com Gimeno (2011), além de atuar no bem-estar e na saúde dos animais, o Médico Veterinário possui responsabilidade na promoção de segurança alimentar, controle de zoonoses e proteção ao meio ambiente. Em estabelecimentos que produzem leite e derivados, é de suma importância a presença deste profissional, pois o mesmo inspeciona a matéria prima para a fabricação dos produtos, orienta funcionários sobre as boas práticas de produção e atua na elaboração de derivados lácteos.

Nesse sentido, objetivo foi avaliar o conhecimento dos residentes de Goiânia e Aparecida de Goiânia sobre a cadeia de produção leiteira e a atuação do Médico Veterinário.

\section{Metodologia}

Foi disponibilizado um questionário composto por 14 questões aplicado via plataforma digital, Google Forms, no mês de maio a julho direcionado para consumidores de leite residentes dos municípios de Goiânia e Aparecida de Goiânia, sendo limitado a 230 respostas. A análise realizada foi apenas descritiva. Após a coleta dos dados foi utilizado os resultados para criar gráficos e tabelas, que foram utilizadas no decorrer do artigo. O questionário aplicado apresentava questões relacionadas à: sexo do entrevistado, faixa etária, nível escolar, município que reside, quantidade de leite consumida 
semanalmente, tipo de leite adquirido, cuidados realizados com o produto antes do consumo, conhecimento sobre a transmissão de doenças via ingestão de leite, entre outras variáveis.

\section{Resultados e discussão}

Foram entrevistados um total de 230 pessoas, sendo que a maioria se encontra na faixa etária de 18 a $28(52,6 \%)$, e o restante entre 29 a $39(20,9 \%)$, de 51 a $60(7,4 \%)$ e idosos (acima de 60 anos) que responderam foram $4,3 \%$ da população analisada. Outrossim, é o grau de escolaridade dos entrevistados sendo que $34,8 \%$ da população possui o superior incompleto, $22,6 \%$ têm segundo grau completo, $29,1 \%$ superior completo, 2,6\% ensino fundamental completo, 6,5\% segundo grau incompleto, $4,3 \%$ de ensino fundamental incompleto. Outro fator analisado foi o município que reside, obtendo resultado de $61,3 \%$ da população entrevistada residem em Goiânia, e das 230 pessoas entrevistas $62,6 \%$ são do sexo feminino.

1. Nome (não obrigatório)

2. Sexo: ( ) Feminino ( ) Masculino ( ) Prefere não informar

3. Faixa etária: ( ) 18-28 ( ) $29-39$ ( ) $40-50$ ( ) $51-60 \quad$ ( ) Acima de 61

4. Escolaridade: ( ) Ensino fundamenta incompleto ( ) Ensino fundamenta completo ( ) Segunda grau incompleto ( ) Segundo grau completo

( ) Superior incompleto ( ) Superior completo

5. Reside no município de: ( ) Goiânia ( ) Aparecida de Goiânia

6. Consumo diário de leite: ( ) Nenhum ( ) 1 a 3 vezes por semana

( ) 4 a 6 vezes por semana ( ) mais de 7 vezes por semana

7. Adquire leite: ( ) UHT (industrializado/caixinha) ( ) Cru (in natura/leiteiro)

8. O que influencia na escolha? (Possivel marcar mais de uma opção):

( ) Valor ( ) Qualidade ( ) Marca

9. Qual forma do produto você consume? (Possível marcar mais de uma opção):

( ) Em pó ( ) Caixinha ( ) Engarrafado ( ) Ensacado

10. Tem conhecimento sobre a transmissão de doenças via ingestão de leite? ( ) Sim ( ) Não

11. Se sim, quais doenças você tem conhecimento? (Possível marcar mais de uma opção):

( ) Brucelose ( ) Toxoplasmose ( ) Tuberculose ( ) Listeriose ( ) Salmonelose

( ) Intoxicação alimentar por estafilococos ( ) Outros:

12. Quais cuidados você tem sobre a compra do leite? (Possivel marcar mais de uma opção):

( ) Armazenar em refrigeração ( ) Armazenar em local não refrigerado

( ) Ferver antes do consumo ( ) Após aberto, armazenar em refrigeração

13. Você possui conhecimento sobre a procedência do leite que você consome? ( ) Sim （ ) Não

14. Em qual das áreas a seguir você acredita que o Médico Veterinário pode atuar dentro da produção de leite?

( ) Nutrição Animal ( ) Inspeção da ordenha (local da retirada do leite) ( ) Qualidade do leite

( ) Inspeção de laticínios ( ) Todas as áreas citadas ( ) Nenhuma das áreas citadas

Figura 1. Questionário conhecimento dos responsáveis do lar sobre a atuação do médico veterinário no controle de qualidade e processo de produção do leite.

O UHT (Ultra High Temperature) por possuir fácil conservação e uso dessa forma tem maior preferência dos consumidores, como demonstrado na figura 2. Além desses motivos, tem longo período de vida comercial quando comparado ao leite cru. Segundo Martins et al. (2008) o leite UHT passa por um processo de esterilização comercial antes de chegar ao consumidor, e mesmo assim dessas 193 pessoas, 31 (13,5\% da população entrevistada) ainda realizam processo de fervura antes de consumir o produto UHT.

Dos 230 (duzentos e trinta) entrevistados 16,1\% (37 pessoas) deles adquirem o leite cru, de forma que 31 desses realizam a fervura antes de consumir, restando 2,5\% da população entrevistada, que não executa esse método antes do consumo. Segundo experimentos de Porcionato et al. (2008), quando o leite foi armazenado cru favoreceu o aumento bactérias, e quando realizado o processo de fervura doméstica a quantidade desses microrganismos diminuiu. Sendo assim, é importante frisar que a fervura do leite cru, é processo necessário para evitar ou diminuir a contaminação do consumidor por micro-organismos patógenos, via ingestão de leite. Além disso, quando leite é adquirido em condições sanitárias de baixa qualidade, com falhas nas boas práticas de fabricação, em condições higiênico- 
sanitárias carentes ou é conservado em temperatura inadequada pode favorecer ao comprometimento das características consideradas ideias do leite, como exemplo, de alteração que o produto pode sofrer é a acidificação do leite (Rosa et al., 2012).

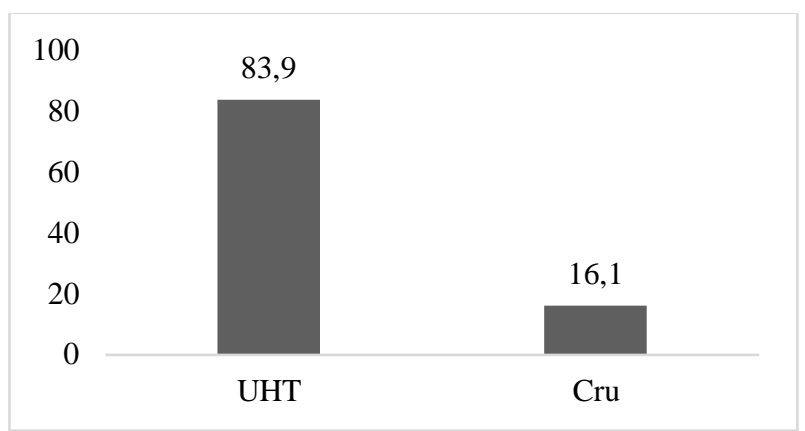

Figura 2. Formas de aquisição do leite (UHT e cru).

Sendo assim, em comparação com resultados dos estudos realizados por Cipro (2016) e este em questão, fica claro a necessidade de realizar a conscientização da população através da educação em saúde. De forma que medidas educativas sejam disponibilizadas para população, focadas em ações e cuidados que o consumidor pode realizar antes de adquirir ou consumir um produto de origem animal. Como formas de implementar essas medidas, seria através do uso de cartazes, palestras, panfletos e outros.

Outro cuidado que $81,7 \%$ (188 pessoas) dos entrevistados executam, é o armazenamento do produto em ambiente refrigerado após aberto. Além de ser recomendação da maioria dos comerciantes, é importante realizá-lo devido após aberto, o produto entrar em contato com ambiente, podendo favorecer a contaminação do mesmo.

Apesar de 92,2\% dos questionados terem o hábito de consumir o leite (UHT ou cru) mais de uma vez por semana, apenas $60,4 \%$ afirmaram ter conhecimento de transmissão de doenças, sendo que as principais doenças estão dispostas na figura 3. Quando comparado com os resultados de Sordi et al. (2015) e Ribeiro Júnior et al. (2020), em suas pesquisas mostraram que grande parte da população não tem conhecimento sobre as doenças transmitidas pelo leite. De acordo com Silva (2018), o leite cru ou in natura, que não passa por um processamento térmico, não apresenta segurança de isenção de patógenos, o que pode resultar em Doenças Transmitidas por Alimento (DTAs).

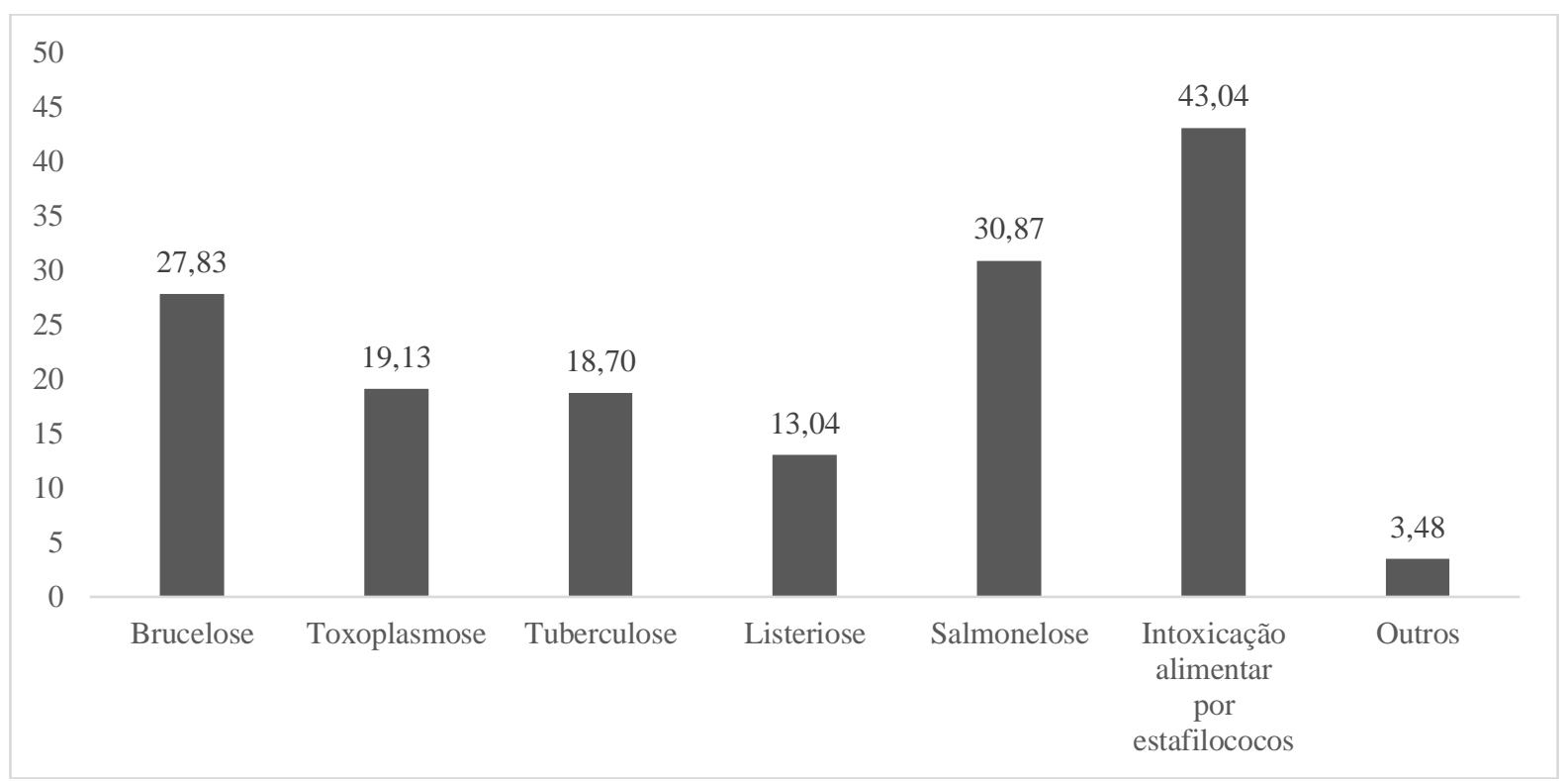

Figura 3. Referente ao conhecimento dos consumidores sobre as doenças transmitidas via ingestão de leite. 
Segundo Borges et al. (2010), o perfil epidemiológico das doenças transmitidas por alimentos não é muito explorado, sendo que há poucos estados e municípios que permite o acesso as estatísticas, assim ampliando os dados para que seja possível identificar os agentes etiológicos mais comuns, população que possui maior riscos, os aspectos que contribuem com a contaminação. Salientando ainda que os dados disponíveis sobre os surtos indicam como agentes etiológicos mais frequentes os de origem bacteriana, entre eles Staphylococcus aureus, Salmonella, Escherichia coli e Clostridium.

A doença que apresentou porcentagem superior na pesquisa foi a intoxicação alimentar por Estafilococos $(64,7 \%)$. De forma que, os principais sintomas descritos na literatura são náuseas, vômito, cãibras abdominais e diarreia, os quais podem ser confundidos com os sintomas de alergias e/ou intolerância ao alimento (Santana et al., 2010). Todavia, não pode ser considerado sinônimos, alergia alimentar a proteína do leite ocorre devido ao não reconhecimento pelo sistema imune, assim o sistema imunológico desencadeia mecanismos de ação contra a proteína para a produção de antígeno causador, provocando os sintomas. Já a intolerância resulta de uma resposta diferente a um alimento ou aditivo, sem que tenha respostas imunológicas, podendo ser ativadas por ação de toxinas produzidas por fungos e/ou bactérias, agentes farmacológicos ou erros metabólicos, principalmente por deficiência enzimática, como a intolerância lactose (Gasparin et al., 2010; Melo et al., 2018; Vasconcellos \& Ito, 2011; Welken et al., 2010). Além disso, os dados apontaram que dos 230 entrevistados 69 (30\%) não tem conhecimento da transmissão de doenças via ingestão de leite e nem da procedência do produto. Sendo que do mesmo total de entrevistados, 230 pessoas, $70(30,43 \%)$ tem conhecimento transmissão de doenças pelo consumo do leite, porém não sabem a procedência do produto que consumem.

De acordo com Oliveira et al. (2010) o leite pode apresentar microrganismos patogênicos mesmo demonstrando boa aparência, odor e sabor. Devido a isso é importante saber a procedência do leite, pois a contaminação pode ocorrer desde a produção, manuseio, transporte, a forma de armazenamento, até os cuidados realizados pelo consumidor (BRASIL, 2011; Forsythe, 2013).

Como mostrado na figura 4, 70,9\% da população entrevistada acreditam que o Médico Veterinário atua em todas as áreas disponibilizadas nas opções. Além dos serviços citados, serviços de auditoria, consultoria ou responsabilidade técnica estão entre os serviços prestados pelo Médico Veterinário que asseguram a qualidade e a segurança dos alimentos de origem animal, protegendo a saúde do consumidor de possíveis perigos veiculados pelo consumo de alimentos de origem animal (Hammerschimidt, 2017; Silva, 2018; Slowinski et al., 2016).

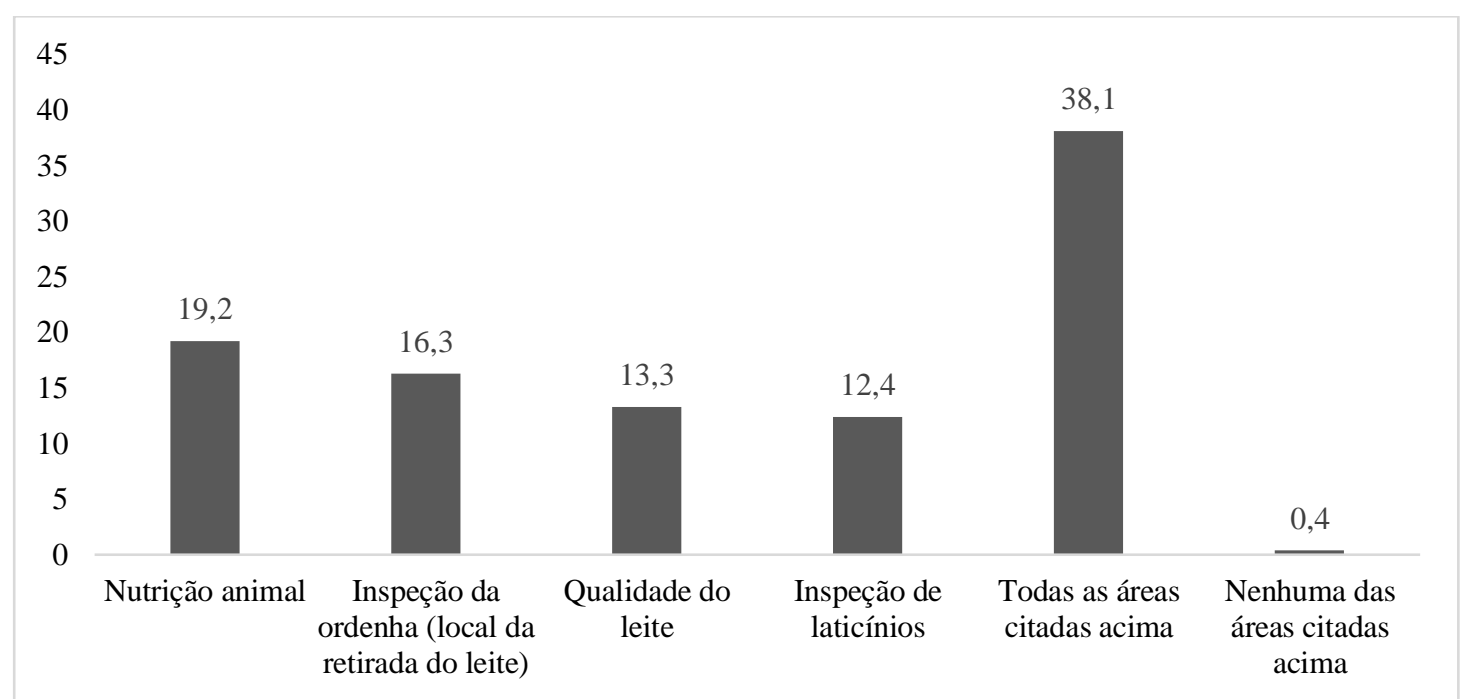

Figura 4. Áreas de atuação do Médico Veterinário na cadeia de produção do leite.

Sendo que no Brasil o ensino em Medicina Veterinária tem como tendência uma formação curativa e individual, que não contempla de forma adequada a área de atuação da Saúde Pública Veterinária, que acaba dificultando a percepção pelos estudantes da importância do Médico Veterinário na proteção da saúde (Bürger, 2010). Ressalta-se que no país, há desvalorização e escassez de 
profissionais capacitados que atuam na área de saúde pública, provocando uma deficiência na formação de Médicos Veterinários que é justificável, pois o perfil da maioria dos alunos é voltado para a atuação na clínica (Cruz et al., 2016).

\section{Referências bibliográficas}

Bodenmüller Filho, A., Damasceno, J. C., Previdelli, I. T. S., Santana, R. G., Ramos, C. E. C. O., \& Santos, G. T. (2010). Typology of production systems based on the milk characteristics. Revista Brasileira de Zootecnia, 39(8), 1832-1839. DOI: https://doi.org/10.1590/S151635982010000800028

Borges, M. F., Andrade, A. P. C. D., \& Machado, T. F. (2010). Salmonelose associada ao consumo de leite e produtos lácteos. In Embrapa Agroindústria Tropical-Documentos. Fortaleza: Embrapa Agroindústria Tropical, 2010.

BRASIL. Ministério de Agricultura, Pecuária e Abastecimento. Instrução Normativa $n^{\circ} 62$ de 29 de dezembro de 2011: Diário Oficial da União. 30 de dezembro de 2011. Disponível em: < http://www.in.gov.br/web/guest/inicio> Acesso em: 25 jul. 2020.

Bürger, K. P. (2010). O ensino de saúde pública veterinária nos cursos de graduação em medicina veterinária do Estado de São Paulo. Universidade Estadual Paulista (UNESP).

Cipro, M. Z. (2016). Conhecimento da população sobre higiene alimentar e consumo de leite $e$ derivados, no distrito de Córrego Rico, Jaboticabal/SP. Universidade Estadual Paulista (UNESP).

Cruz, C. A., Olivari, M. B. D., Paula, E. M. N., Bartoli, R. B. M., \& Bürger, K. P. (2016). Novos desafios para a saúde pública veterinária. Revista de Ciência Veterinária e Saúde Pública, 3, 208210.

De Vries, M., Bokkers, E. A. M., Dijkstra, T., van Schaik, G., \& De Boer, I. J. M. (2011). Invited review: Associations between variables of routine herd data and dairy cattle welfare indicators. Journal of Dairy Science, 94(7), 3213-3228. DOI: https://doi.org/10.3168/jds.2011-4169

Forsythe, S. J. (2013). Microbiologia da segurança dos alimentos. Artmed.

Gasparin, F. S. R., Carvalho, J. M. T., \& Araujo, S. C. (2010). Alergia à proteína do leite de vaca versus intolerância à lactose: As diferenças e semelhanças. Saúde e Pesquisa, 3(1).

Gimeno, E. J. (2011). El legado de Bourgelat a la veterinaria moderna (pp. 321-329).

Hammerschimidt, J. (2017). O prontuário médico veterinário: requisitos e importância. In R. A. Tostes, S. T. J. Reis, \& V. V Castilho (Eds.), Tratado de Medicina Veterinária Legal. Medvep.

Lima, A. S., Lima, R. F., Silva, E. V., Targino, A. N., \& Targino, M. V. P. (2016). Padrões físicoquímico e microbiológicos do leite cru comercializado em município no interior da Paraíba. Revista Verde de Agroecologia e Desenvolvimento Sustentável, 11(3), 80-85. DOI: https://doi.org/10.18378/rvads.v11i3.4223

Martins, A. M. C. V., Rossi Junior, O. D., Salotti, B. M., Bürger, K. P., Cortez, A. L. L., \& Cardozo, M. V. (2008). Efeito do processamento UAT (Ultra Alta Temperatura) sobre as características físico-químicas do leite. Food Science and Technology, 28(2), 295-298. DOI: https://doi.org/10.1590/s0101-20612008000200005

Matsubara, M. T., Beloti, V., Tamanini, R., Fagnani, R., Silva, L. C. C., Monteiro, A. A., Battaglini, A. P. P., Ortolani, M. B. T., \& Barros, M. A. F. (2011). Boas práticas de ordenha para redução da contaminação microbiológica do leite no agreste Pernambucano. Semina: Ciências Agrárias, 32(1), 277-285. DOI: https://doi.org/10.5433/1679-0359.2011v32n1p277

Melo, E. S., Amorim, W. R., Pinheiro, R. E. E., Corrêa, P. G. N., Carvalho, S. M. R., Santos, A. R. S. S., Barros, D. S., Oliveira, E. T. A. C., Mendes, C. A., \& Sousa, F. V. (2018). Doenças transmitidas por alimentos e principais agentes bacterianos envolvidos em surtos no Brasil. PUBVET, 12(10), 1 9. DOI: https://doi.org/10.31533/pubvet.v12n10a191.1-9

Oliveira, A. B. A., Paula, C. M. D., Capalonga, R., Cardoso, M. R. I., \& Tondo, E. C. (2010). Doenças transmitidas por alimentos, principais agentes etiológicos e aspectos gerais: uma revisão. Revista HCPA, 30(6/7), 279-285.

Porcionato, M. A. F., Reis, C. B. M., Barreiro, J. R., Moreno, J. F. G., \& Mestieri, L. (2008). Efeito da 
fervura, resfriamento ou congelamento na qualidade do leite cru. Revista Acadêmica Ciência Animal, 6(4), 511-517. DOI: https://doi.org/10.7213/cienciaanimal.v6i4.11642

Ribeiro Júnior, J. C., Santos, I. G. C., Dias, B. P., Mendes, L. P., \& Barbon, A. P. A. C. (2020). Perfil do consumidor brasileiro e hábitos de consumo de leite e derivados. Archives of Veterinary Science, 25(2). DOI: https://doi.org/10.5380/avs.v25i2.72429

Rosa, D. C., Trentin, J. M., Pessoa, G. A., Silva, C. A. M., \& Rubin, M. I. B. (2012). Qualidade do leite em amostras individuais e de tanque de vacas leiteiras. Arquivos Do Instituto Biológico, 79(4), 485-493. DOI: https://doi.org/10.1590/s1808-16572012000400004

Santana, E. H. W., Beloti, V., Aragon-Alegro, L. C., \& Mendonça, M. B. O. C. (2010). Estafilococos em alimentos. Arquivos Do Instituto Biológico, 77(3), 545-554. DOI: https://doi.org/10.1590/1808$\underline{1657 \mathrm{v} 77 \mathrm{p} 5452010}$

Silva, F. M. (2018). A inserção do médico veterinário na estratégia saúde da família: desafios e perspectivas-relato de experiência. Universidade Federal do Pampa.

Silva, M. V. R., \& Coelho, A. (2019). Causas, sintomas e diagnóstico da intolerância à lactose e alergia ao leite de vaca. Revista Saúde UniToledo, 3(1).

Slowinski, K., Tremori, T. M., Massad, M. R. R., Tasaka, A. C., \& Rocha, N. S. (2016). Responsabilidade ética e civil do médico-veterinário no ambiente hospitalar. Revista de Educação Continuada Em Medicina Veterinária e Zootecnia Do CRMV-SP, 14(2), 30-37.

Sordi, E., Skonieski, F. R., Castamann, A., \& Zocche, F. (2015). Perfil do consumidor de leite na cidade de Erechim-RS. Revista Brasileira de Tecnologia, 9(2), 1836-1846. DOI: https://doi.org/10.3895/rbta.v9n2.1654

Vasconcellos, S. A., \& Ito, F. H. (2011). Principais zoonoses transmitidas pelo leite. Atualização. Revista de Educação Continuada em Medicina Veterinária e Zootecnia do CRMV-SP, 9(1), 32-37. DOI: https://doi.org/10.36440/recmvz.v9i1.388

Welken, C. A., Both, J. M. C., Longaray, S. M., Haas, S., Soeiro, M. L. T., Ramos, R. C., Welker, C. A. D., Both, J. M. C., Longaray, S. M., Haas, S., Soeiro, M. L. T., \& Ramos, R. C. (2010). Análise microbiológica dos alimentos envolvidos em surtos de doenças transmitidas por alimentos (DTA) ocorridos no estado do Rio Grande do Sul, Brasil. Revista Brasileira de Biociências, 8(1), 44-48.

Histórico do artigo:

Recebido: 24 de março de 2021.

Aprovado: 2 de maio de 2021.
Licenciamento: Este artigo é publicado na modalidade Acesso Aberto sob a licença Creative Commons Atribuição 4.0 (CC-BY 4.0), a qual permite uso irrestrito, distribuição, reprodução em qualquer meio, desde que $\mathrm{o}$ autor $\mathrm{e}$ a fonte sejam devidamente creditados. 